\title{
Esthetic restoration of the smile: directly veneering a discolored anterior tooth
}

\begin{abstract}
- Polliana Mendes Candia Scaffa Department of Biological Sciences, Bauru School of Dentistry, University of São Paulo, Bauru, SP, Brazil • Luciana Mendonça Silva Department of Operative Dentistry, School of Dentistry, Federal University of Amazonas, Manaus, AM, Brazil • Flavia Pardo Salata Nahsan Federal University of Sergipe, Lagarto, SE, Brazil • Paula Costa Pinheiro Sampaio Department of Operative Dentistry, School of Dentistry, University of Brasília, Brasília, DF, Brazil - Paulo Afonso Silveira Francisconi Department of Operative Dentistry, Endodontics and Dental Materials, Bauru School of Dentistry, University of São Paulo, Bauru, SP, Brazil • Luciana Fávaro Francisconi-dos-Rios Department of Operative Dentistry, School of Dentistry, University of São Paulo, São Paulo, SP, Brazil
\end{abstract}

ABSTRACT | Esthetic restoration of the smile: directly veneering a discolored anterior tooth• Case report: Although direct composite veneering discolored anterior teeth is quite widespread, proper reproduction of their natural appearance requires much from the professional. The whole treatment of a severely discolored upper central incisor, from planning to finishing and polishing, through its direct veneering is critically reported. Relevance: Direct composite laminate veneers are, indeed, a viable treatment option to correct esthetic abnormalities involving most of the labial surface of anterior teeth. Since accurately performed by well qualified dentists, this relative conservative therapy will provide esthetic, functional and emotional rehabilitation to the patient, resulting in a harmonious and pleasant smile.

DESCRIPTORS | Composite Resins; Dental Veneers; Dental Esthetics; Incisor; Tooth Discoloration.

RESUMO | Recuperação estética do sorriso: faceta laminada direta em dente anterior escurecido • Relato de caso: Ainda que a execução de facetas laminadas diretas de resina composta em dentes anteriores seja amplamente difundida, a adequada reprodução de seus aspectos naturais exige muito do profissional. Todo o tratamento de um incisivo central superior severamente escurecido, desde o planejamento ao acabamento e polimento, por meio da confecção de uma faceta laminada direta, é criticamente descrito. Relevância: Facetas laminadas diretas de resina composta são, certamente, uma opção de tratamento viável para corrigir anormalidades estéticas que envolvam a maior parte da superfície dos dentes anteriores. Esta terapia relativamente conservadora, desde que adequadamente conduzida pelo cirurgião-dentista qualificado, proporcionará a reabilitação estética, funcional e emocional ao paciente, culminando em um sorriso harmonioso e agradável.

DESCRITORES ～Resinas Compostas; Facetas Dentárias; Estética Dentária; Incisivo; Descoloração de Dente.

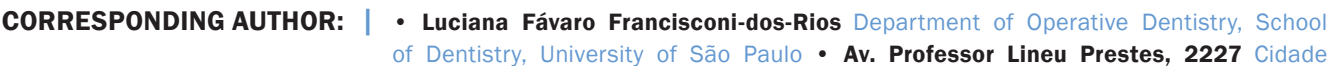

Universitária, SP, Brazil • 05508-000 E-mail: luff@usp.br

- Received Mar 06, 2015 • Accepted May 05, 2015

- Dol http://dx.doi.org/10.11606/issn.2357-8041.clrd.2015.90796 


\section{INTRODUCTION}

Laminate veneers, which may be processed directly or indirectly, are didactically indicated to correct esthetic abnormalities which impair two thirds or more of the labial surface of anterior teeth: discolorations, displeasing shapes or contours, lack of size and/or volume and extensive lesions/restorations, for instance., ${ }^{1,2}$

Veneering such teeth, after proper preparation, with direct resin composite is a favorable treatment option perhaps mainly due to the possibility of greater conservation of tooth structure. ${ }^{3}$ Machado et al. ${ }^{4}$ have demonstrated that even if teeth undergoing veneer preparations are related to significant mass losses compared to unprepared teeth, direct composite veneer preparations result in lower mass losses than the conventional indirect ceramic veneer preparations. Direct composite laminate veneers are also related to fewer expenses in comparison with its indirect counterparts; this treatment is relative reversible and there is no need for further cementation steps. In addition, intraoral polishing is simple, and any cracks or fractures can be easily repaired, while the marginal adaptation is better than that of indirect laminate veneer restorations. ${ }^{1}$ In contrast to the proclaimed main disadvantages of direct laminate veneers, namely low resistance to wear and susceptibility to discoloration and fractures, ${ }^{1}$ Rosentritt et al. ${ }^{5}$ found comparable resistance to toothbrush abrasion and failure rates between them and ceramic veneers, both of which being related to satisfying longevity under aging.

Still concerning ceramic veneers, it is worth considering that minimum thickness ones are gradually being incorporated to state of art veneering. However, regardless of the already known advantages and limitations, such alternative is indicated to improve esthetics by changing the form and texture of teeth explicitly with no severe discoloration. ${ }^{6}$
Despite being one of the multiple factors that leads to the balance of a harmonious smile, the color of teeth is one of the first noticed when misrepresented. Discoloration can be located over the tooth structure (extrinsic stains) or inside of it (intrinsic stains); intrinsic stains can be derived from either pre or post-eruptive causes: discoloration of non-vital teeth is usually associated with the phenomenon of pulpal necrosis. ${ }^{7}$

Restoring discolored endodontically treated teeth is not always simple, particularly when only one of the anterior teeth, which already have not answered to bleaching, is involved in the treatment plan. The decision on treatment depends on the degree of discoloration, the quantity and quality of remaining dental structure, biological distances, position of teeth, analysis of the occlusion and on the expectations and possibilities of the patient. Accordingly, contemporary dentistry offers different options for such clinical situation, such as masking and simulation techniques with direct or indirect composite and ceramic laminate veneers, as well as full coverage crowns. ${ }^{8}$

Although direct composite laminate veneers are rather indicated for treating discolored teeth, to the proper reproduction of their optical appearance deep knowledge and skills are required. Therefore, not only should clinicians have a scientific technique for restoration of dental biology and function, but also their esthetic sense should direct them in the reproduction of polychromatic and anatomic features of the tooth, rendering the restoration imperceptible. ${ }^{9}$

Thus, a step-by-step clinical protocol for the restoration of a severely discolored tooth through its direct veneering is described.

\section{CASE REPORT}

A 30 year-old female patient went to the Bauru School of Dentistry postgraduate clinic dissatisfied with the color and shape of her endodontically 
treated maxillary right central incisor (\#11; Figure 1 and Figure 2), which had already been bleached. She was well-versed in the various treatment options and then, after considering all advantages and limitations of different techniques and materials, she chose the direct composite laminate veneer.

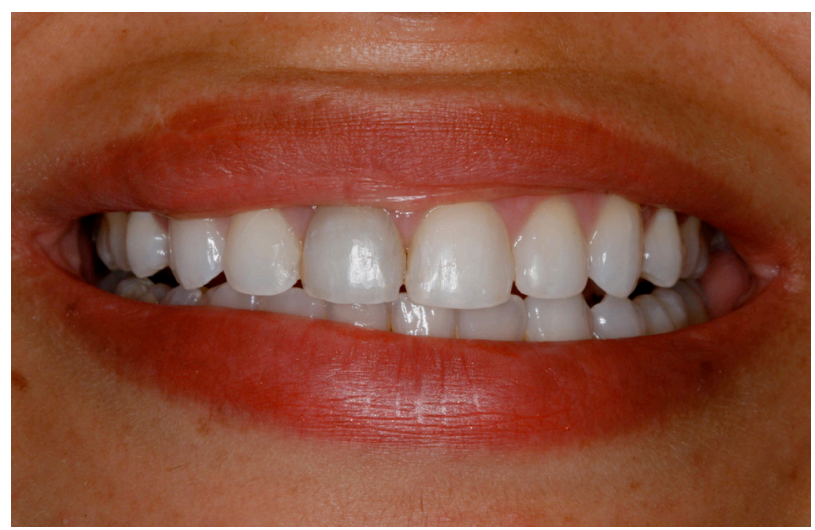

Figure 1 | Smile of a 30 year-old female patient dissatisfied with the color and shape of her endodontically treated maxillary right central incisor.

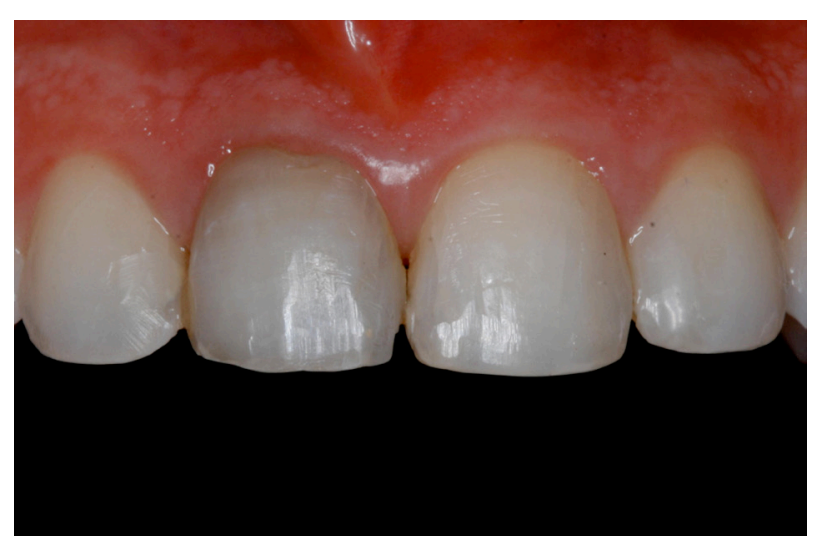

Figure 2 | Preoperative aspect of the discolored maxillary right central incisor (\#11), which was already bleached.

\section{Preoperative Procedures}

In an appointment prior to the restorative approach, followed by the anamnesis and a clinical examination, as well as dental prophylaxis with pumice, the selection of the proper resin shades was accomplished based on the maxillary left central incisor (\#21; Figure 3). A careful visual analysis of tooth \#21 allowed professionals to outline its primary features, which would be reproduced in the restoration of tooth \#11.

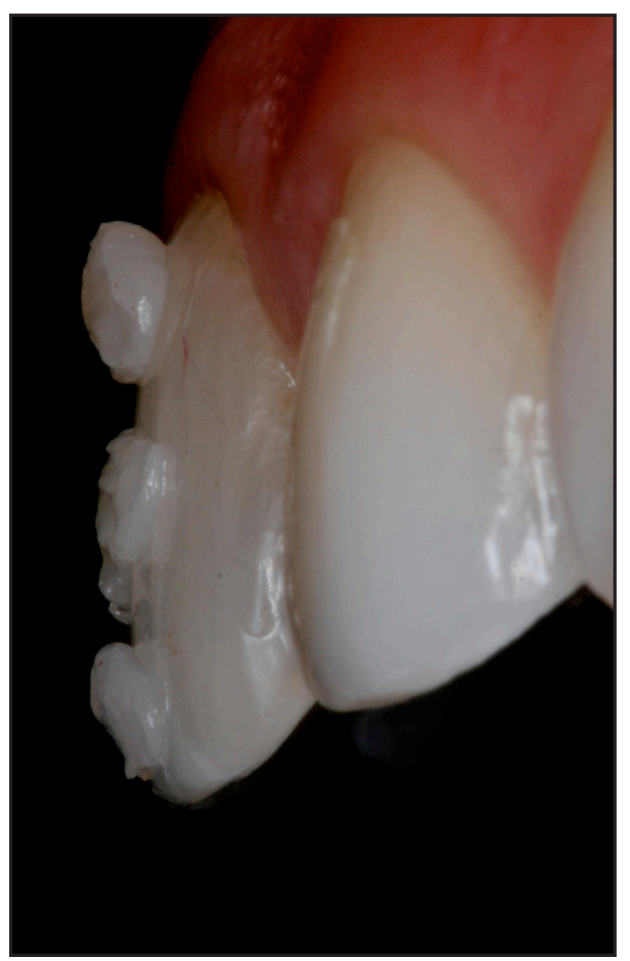

Figure 3 || Shade selection based on the maxillary left central incisor (\# 21).

To achieve not only a functionally successful, but also a natural-appearing direct composite veneer, the clinician must have a comprehensive knowledge on the optical properties of the tooth and the dimensions of color. Shade selection is not an easy task: professionals should identify details and understand the factors interacting in the polychromatism of a tooth. It is well-known that the appearance of a tooth is determined by the correlation between enamel and dentin during the process of refraction and reflection of light waves. While dentin gives the tooth chroma, opacity, and fluorescence, enamel modifies the aspect of dentin by providing translucency and opalescence. Thus, clinicians should have a simple and accurate technique for shade interpretation, for the identification of different tooth regions and for their reproductionwith the restoration. ${ }^{9}$ Central 
incisors are the dominant teeth and should present similar characteristics among each other to allow a harmonious and balanced smile.

To favor visualization of which wear would be achieved by tooth preparation, in both mesio-distal and cervico-incisal dimensions, silicon guides were obtained from the molding of anterior teeth. Two impressions of these teeth were obtained with selected silicon. One of them was transversally sectioned and the other was longitudinally sectioned. The positioning of impressions and the observation of teeth in incisal and profile aspects, in Figure 4 and Figure 5, correspondingly, allow the professionals to observe the various facial planes of the tooth and the depth of preparation in distinct areas of the tooth: cervical, midfacial, and incisal.

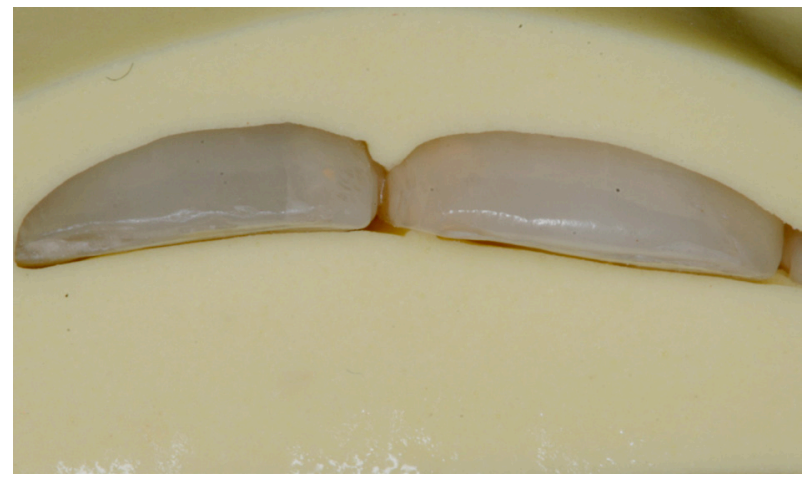

Figure 4 || Transversally sectioned silicon guide positioned to allow the observation of central incisors in an incisal aspect.

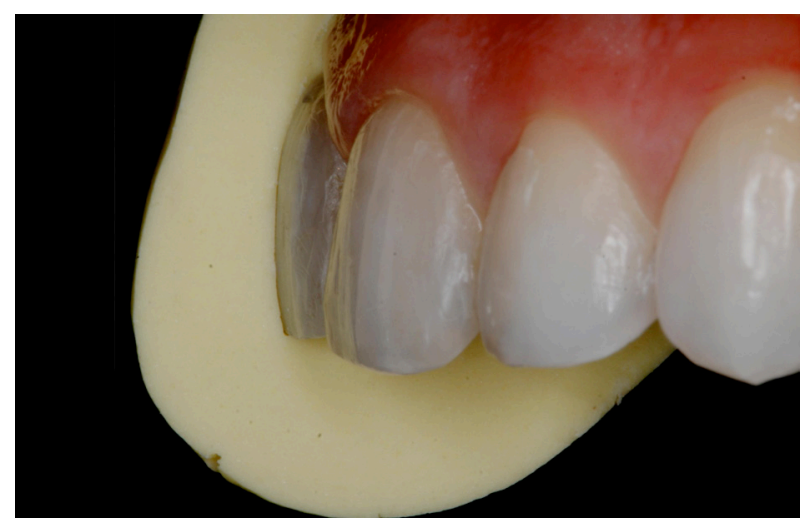

Figure 5 | Longitudinally sectioned silicon guide positioned to allow the observation of the maxillary right central incisor in a profile aspect.

\section{Tooth Preparation}

The tooth was initially prepared by determining the cervical reduction groove, extended through proximal edges until the incisal region, with a 1.4 mm diameter sphere diamond (\#1014 KG Sorensen Indústria e Comércio Ltda, Barueri, SP, Brazil). Depth cut was prepared to the half depth of the diamond $(\sim 0.7 \mathrm{~mm})$ as seen in Figure 6.

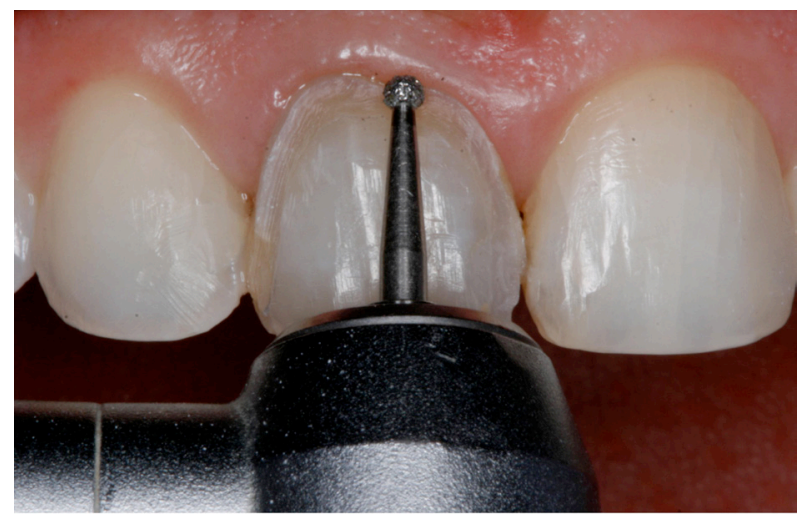

Figure 6 | Determining a $\sim 0.7 \mathrm{~mm}$ deep cervical reduction groove, extended through proximal edges until the incisal region, with a $1.4 \mathrm{~mm}$ diameter sphere diamond (\#1014).

Then, three facial cervico-incisal reduction grooves, i.e. mesial, central and distal ones, were prepared according to anterior teeth three facial planes, using half depth $(\sim 0.8 \mathrm{~mm})$ of a $1.6 \mathrm{~mm}$ diameter round end cylinder diamond (\#2135 KG Sorensen Indústria e Comércio Ltda, Barueri, SP, Brazil) (Figure 7). Following cervical, midfacial and incisal planes during facial reduction is extremely important: inadvertent exposure of dentin may adversely affect the pulp-dentin complex and spaces with variable thickness for accommodation of the composite may result in esthetic discrepancies. Remaining tissue between central and mesial facial reduction grooves was first worn out, as determined by the silhouette technique. After careful observation of the partially prepared tooth, to confirm the uniformity of wear, the tissue between central and distal facial reduction grooves was 
worn out. Preparation was, then, complemented by extending it slightly facial to the interproximal contact area.

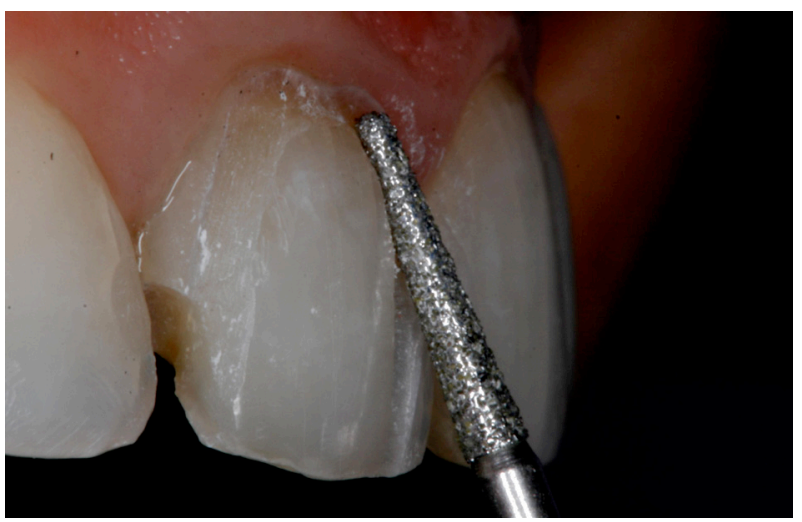

Figure 7 | Determining the facial cervico-incisal central reduction groove, according to anterior teeth three facial planes, using half depth $(\sim 0.8 \mathrm{~mm})$ of a $1.6 \mathrm{~mm}$ diameter round-ended cylinder diamond (\#2135).

Silicon guides were taken into position and the prepared tooth was observed in incisal (Figure 8) and profile (Figure 9) aspects to check wear accurateness. Preparation was slightly extended to the subgingival level ( 0.5 mm), determining a chamfer circumferentially, and then, finished with a fine grain round-ended cylinder diamond (\#2135F; KG Sorensen Indústria e Comércio Ltda, Barueri, SP, Brazil; Figure 10).

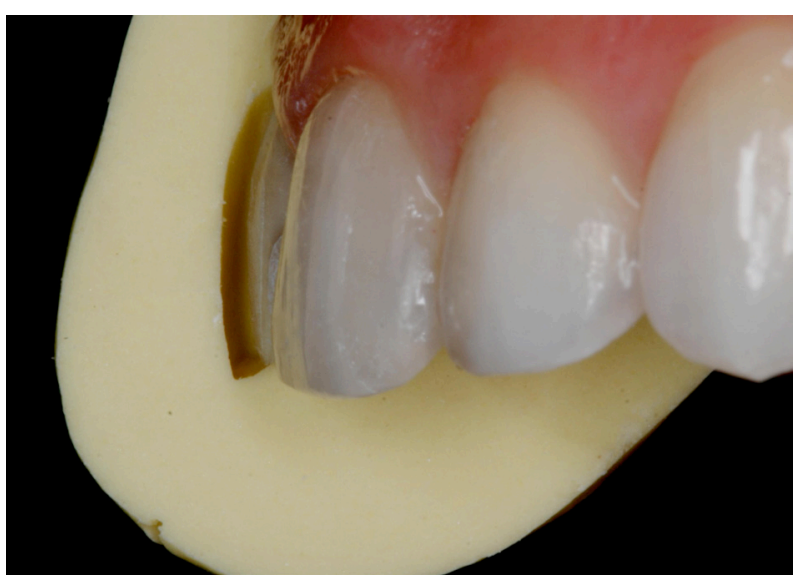

Figure 8 | Transversally sectioned silicon guide positioned to allow the observation of the prepared tooth in the incisal aspect.

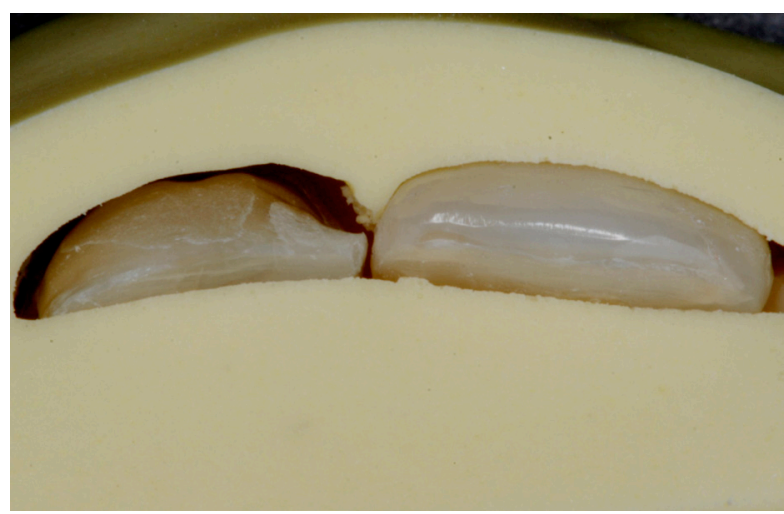

Figure 9 | Longitudinally sectioned silicon guide positioned to allow the observation of the prepared tooth was observed in the profile aspect.

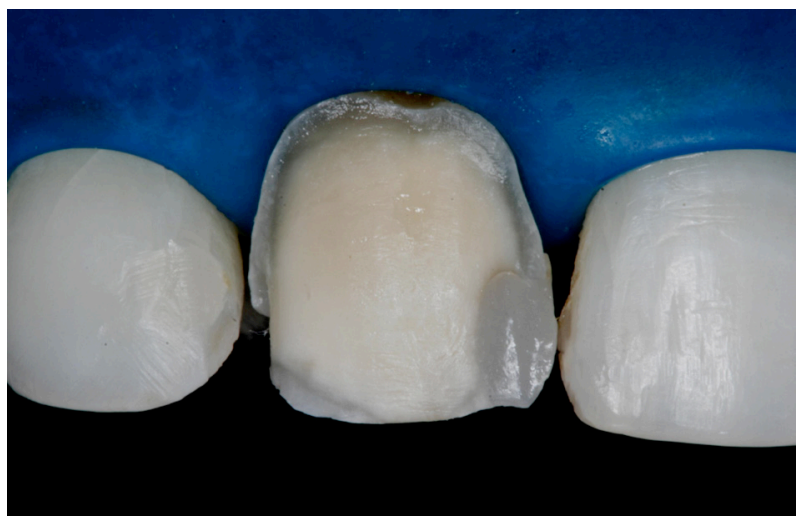

Figure 10 | Preparation after slightly extension to the subgingival level $(\sim 0.5 \mathrm{~mm})$, and finishing with a fine grain round ended cylinder diamond (\#2135F).

\section{Adhesive Procedures}

After rubber dam isolation, a polyester strip was used to isolate adjacent teeth. Following $15 \mathrm{~s}$ of acid etching (37\% phosphoric acid gel, Etching Dental Gel ${ }^{\circledR}$, Dentsply Indústria e Comércio Ltda, Rio de Janeiro, RJ, Brazil), and 30 s of water washing, an absorbent paper was used to determine moist dentin. Two coats of the adhesive system Adper ${ }^{\mathrm{TM}}$ Single Bond $2^{\circledR}$ (3M ESPE, St. Paul, MN, USA) were actively applied (15 s) and, after the assisted solvent evaporation, light activation was performed (10 s/1,000 $\mathrm{mW} / \mathrm{cm}^{2}$; Radii-cal ${ }^{\circledR}$, SDI Limited, Bayswater, VIC, Australia). 


\section{Placement of Resin Composite}

A layer of a white opaque resin composite (WO Esthet- $\mathrm{X}^{\circledR}$ Micro Matrix Restorative, Dentsply Indústria e Comércio Ltda, Rio de Janeiro, RJ, Brazil) was used to mask the dark gray color of the dentin. After blocking the stained background, distinct structures and optical features of the tooth were reproduced by using various resin shades, in agreement with the peculiarities of each region of the tooth, seeking for a gradual transition among them. The correct thickness of different composite layers is fundamental to achieve a natural appearance by the restoration. Any mistake during the application of resin composite may lead to an excessively translucent or opaque restoration. The cervical region received A3 dentin shade resin (Figure 11), the medium third was restored with A2 dentin shade resin, and the incisal area with A1 dentin shade resin (4 Seasons System, Ivoclar Vivadent Ltda, São Paulo, SP, Brazil). Additionally, lost enamel was substituted by an A2 translucent resin, for cervical and medium-thirds, and by A1 translucent resin, for the incisal third (4 Seasons System, Ivoclar Vivadent Ltda, São Paulo, SP, Brazil). A superficial layer of medium value enamel resin (4 Seasons System, Ivoclar Vivadent Ltda, São Paulo, SP, Brazil) was added over the entire labial surface (Figure 12).

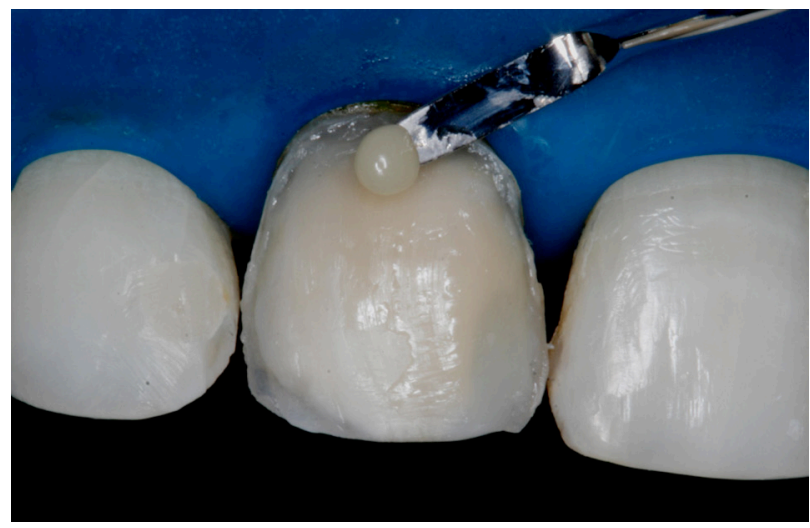

Figure 11 | After blocking the stained background, application of an $\mathrm{A} 3$ dentin shade resin increment on the cervical region.

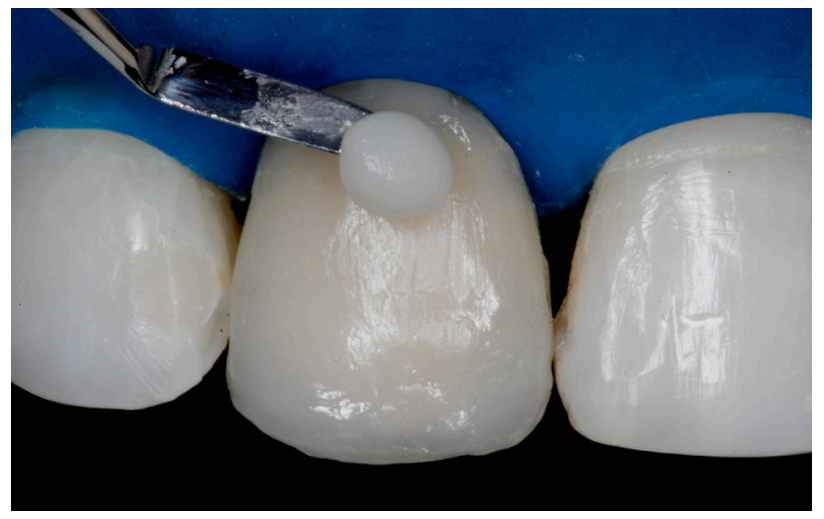

Figure 12 | Application of a superficial layer of medium value enamel resin over the entire labial surface.

A resin composite placement instrument and a contouring brush (Figure 13) were used to shape and to give some texture to such material. Each composite increment was light activated for $20 \mathrm{~s}$. After the last increment placement, restoration was light activated for $40 \mathrm{~s}\left(1,000 \mathrm{~mW} / \mathrm{cm}^{2}\right.$; Radii-cal ${ }^{\circledR}$, SDI Limited, Bayswater, VIC, Australia).

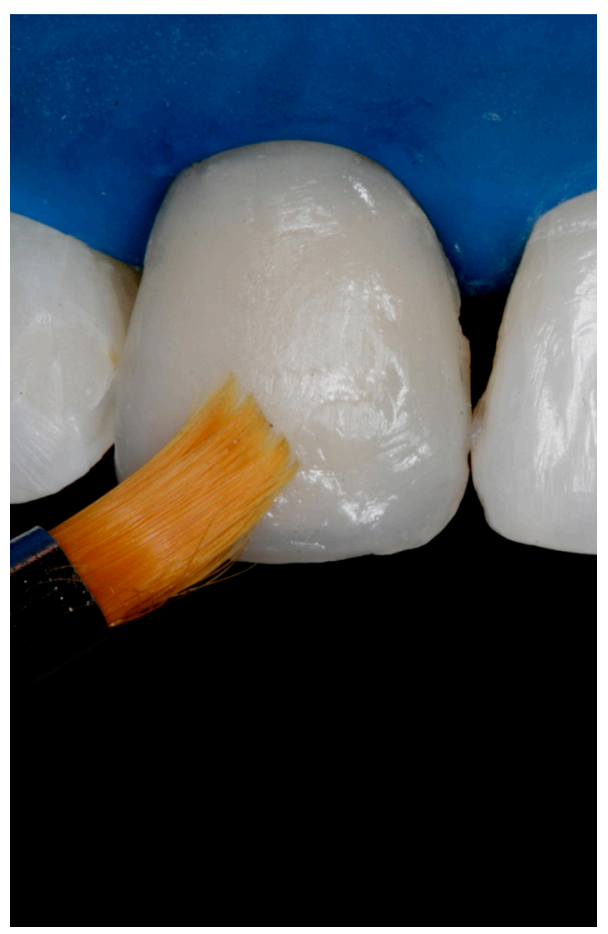

Figure 13 | Using a resin composite placement instrument and a contouring brush toshape and to give texture to such material. 


\section{Finishing and Polishing}

After the rubber dam being removed, a flexible abrasive disk (Sof-Lex ${ }^{\mathrm{TM}}$ Extra Thin Contouring and Polishing Disc, $3 \mathrm{M}^{\mathrm{TM}}$ ESPE $^{\mathrm{TM}}$, Sumaré, SP, Brazil) was used for the removal of the main excesses. Shaping, contouring, and smoothing processes were performed on a second section with a series of finishing burs (KG Sorensen Indústria e Comércio Ltda, Barueri, SP, Brazil) and flexible disks (Sof-Lex ${ }^{\mathrm{TM}}$ Extra Thin Contouring and Polishing Disc, $3 \mathrm{M}^{\mathrm{TM}} \mathrm{ESPE}^{\mathrm{TM}}$, Sumaré, SP, Brazil). Then, finishing strips were finally employed according to their grit. Subsequent polishing with a diamond polishing paste in association to felt disks was also achieved.

Treatment successfulness (Figure 14 and Figure 15) was confirmed in a further section, immediately attending patients' and professionals' expectations. However, the follow up is essential to conserve good results over time.

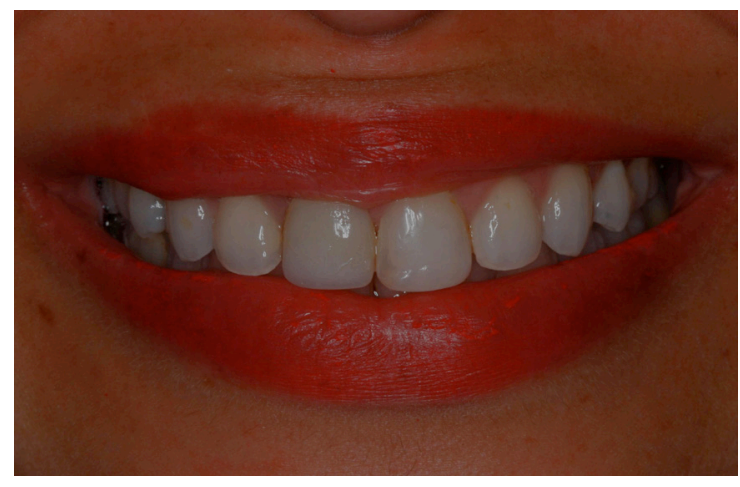

Figure 14 | Postoperative aspect of the smile.

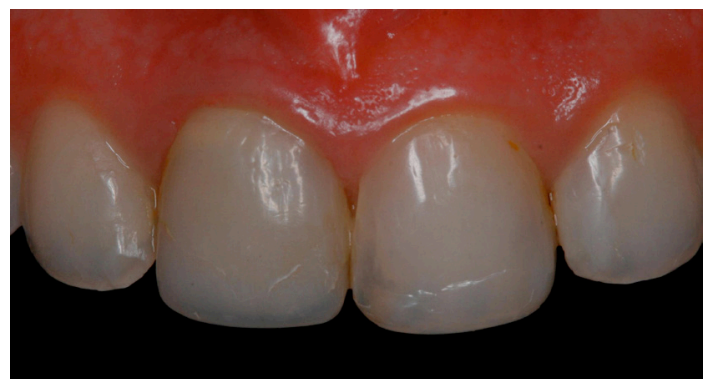

Figure 15 | Postoperative aspect of the veneered maxillary right central incisor (\#11), after finishing and polishing.

\section{CONCLUSIONS}

Direct composite veneering is continuously being proved to be a viable treatment alternative for numerous cases, ${ }^{1,2}$ that specially include discolored teeth. A clinical study, ${ }^{10}$ which compared the opinion of patients regarding cosmetic improvement after direct composite or indirect porcelain veneering of their teeth, showed there were no differences between such approaches. However, a preference towards accepting the composite veneer option was noted. Accordingly, contemporary dentistry truly encourages practitioners to implement relative conservative therapies before moving on to more invasive ones. ${ }^{8}$ Directly re-establishing the lost dental esthetic appearance of a patient is not always simple and depends upon the ability and the deep knowledge of the clinician. It is up to a well qualified dentist, when directly veneering a discolored anterior tooth, to perform all clinical steps with excellence, from the planning to the follow-up, assigning the patient esthetic, functional and emotional rehabilitation.

\section{ACKNOWLEDGMENTS}

PMC Scaffa, LM Silva, FPS Nahsan, PCP Sampaio and LF Francisconi-dos-Rios thank, on behalf of its current Director, Professor Maria Aparecida de Andrade Moreira Machado, Bauru School of Dentistry of the University of São Paulo for enabling the reported case to be conducted during their graduate training in Operative Dentistry.

\section{REFERENCES}

1. Korkut B, Yanıkoğlu F, Günday M. Direct composite laminate veneers: three case reports. J Dent Res Dent Clin Dent Prospects. 2013;7(2):105-11. doi: 10.5681/joddd.2013.019.

2. Radz GM. Minimum thickness anterior porcelain restorations. Dent Clin North Am. 2011 Apr;55(2):353-70, doi: 10.1016/j.cden.2011.01.006. 
3. Felippe LA, Baratieri LN. Direct resin composite veneers. Masking the dark prepared enamel surface. Quintessence Int. 2000 Sep;31(8):557-62.

4. Machado AN, Coelho-de-Souza FH, Rolla JN, Erhardt MC, Demarco FF. Direct or indirect composite veneers in anterior teeth: which method causes higher tooth mass loss? An in vitro study. Gen Dent. 2014 Nov-Dec;62(6):55-7.

5. Rosentritt M, Sawaljanow A, Behr M, Kolbeck C, Preis V. Effect of tooth brush abrasion and thermo-mechanical loading on direct and indirect veneer restorations. Clin Oral Investig. 2015 Jan;19(1):53-6o. doi: 10.1007/s00784-014-1209-2.

6. da Cunha LF, Reis R, Santana L, Romanini JC, Carvalho RM, Furuse AY. Ceramic veneers with minimum preparation. Eur J Dent. 2013 Oct;7(4):492-6. doi: 10.4103/1305-7456.120645.
7. Nathoo AS. The chemistry and mechanisms of extrinsic and intrinsic discoloration. J Am Dent Assoc. 1997 Apr;128 Suppl:6S-10S. doi: 10.14219/jada.archive.1997.0428.

8. Barber AJ, King PA. Management of the single discoloured tooth. Part 2: restorative options. Dent Update. 2014 Apr;41(3):194-6, 198-200, 202-4.

9. Franco EB, Francischone CE, Medina-Valdivia JR, Baseggio W. Reproducing the natural aspects of dental tissues with resin composites in proximoincisal restorations. Quintessence Int. 2007 Jun;38(6):505-10.

10. Nalbandian S, Millar BJ. The effect of veneers on cosmetic improvement. Br Dent J. 2009 Jul 25;207(2):E3; discussion 72-3. doi: 10.1038/sj.bdj.2009.609. 